\title{
THE PHENOLOGY OF HEXACENTRUS MUNDUS (F. WALKER) AT WAU, PAPUA NEW GUINEA (ORTHOPTERA, TETTIGONIIDAE)
}

\author{
By Michael H. Robinson ${ }^{1}$ and Thane Pratt ${ }^{2}$
}

\section{INTRODUCTION}

When at Wau, Morobe District, Papua New Guinea, during 1970-1971, the senior author was impressed by the very distinctive nature of the stridulation of a common tettigoniid Hexacentrus mundus (F. Walker). No attempt was made to study the species at this stage but it was encountered frequently during other researches and males appeared to be stridulating throughout the entire year. Phenological studies of the spiders at Wau (Robinson \& Robinson, 1973; Robinson, Lubin \& Robinson, 1974) showed that adult spiders of several species were active and reproducing throughout the year and gave rise to the suggestion that tropical arthropods may be less seasonal at middle altitudes than they are in the lowlands. Nearly all the sparse data on the phenology of tropical insects come from lowland study areas (see review in Robinson, Lubin \& Robinson ibid.). We therefore decided to census the number of singing male $H$. mundus that were audible from three line transects located at around ro66 meters altitude. We carried out this survey, weekly, for one year (January 1974 to December 1974). We originally chose to census $H$. mundus because its song sounded unique among the orthopteran stridulations at Wau; it turned out to be a lucky choice since the insect is almost certainly predatory and therefore more interesting for comparisons with the spider data that are already available from this locality. Stridulation is essentially a sexual activity and the census should provide an index of reproductively active individuals. It showed that males were active in every one of the months of the year.

\section{Materials ANd Methods}

\section{The species}

The species was identified by Prof. I. J. Cantrall, Museum of Zoology, Ann Arbor, Michigan, to whom we are most grateful.

\footnotetext{
${ }^{1}$ Smithsonian Tropical Research Institute, P.O. Box 2072, Balboa, Panama Canal Zone.

${ }^{2}$ Wau Ecology Institute, P.O. Box 77, Wau, Papua New Guinea.

Manuscript received by the editor September 15, 1975.
} 


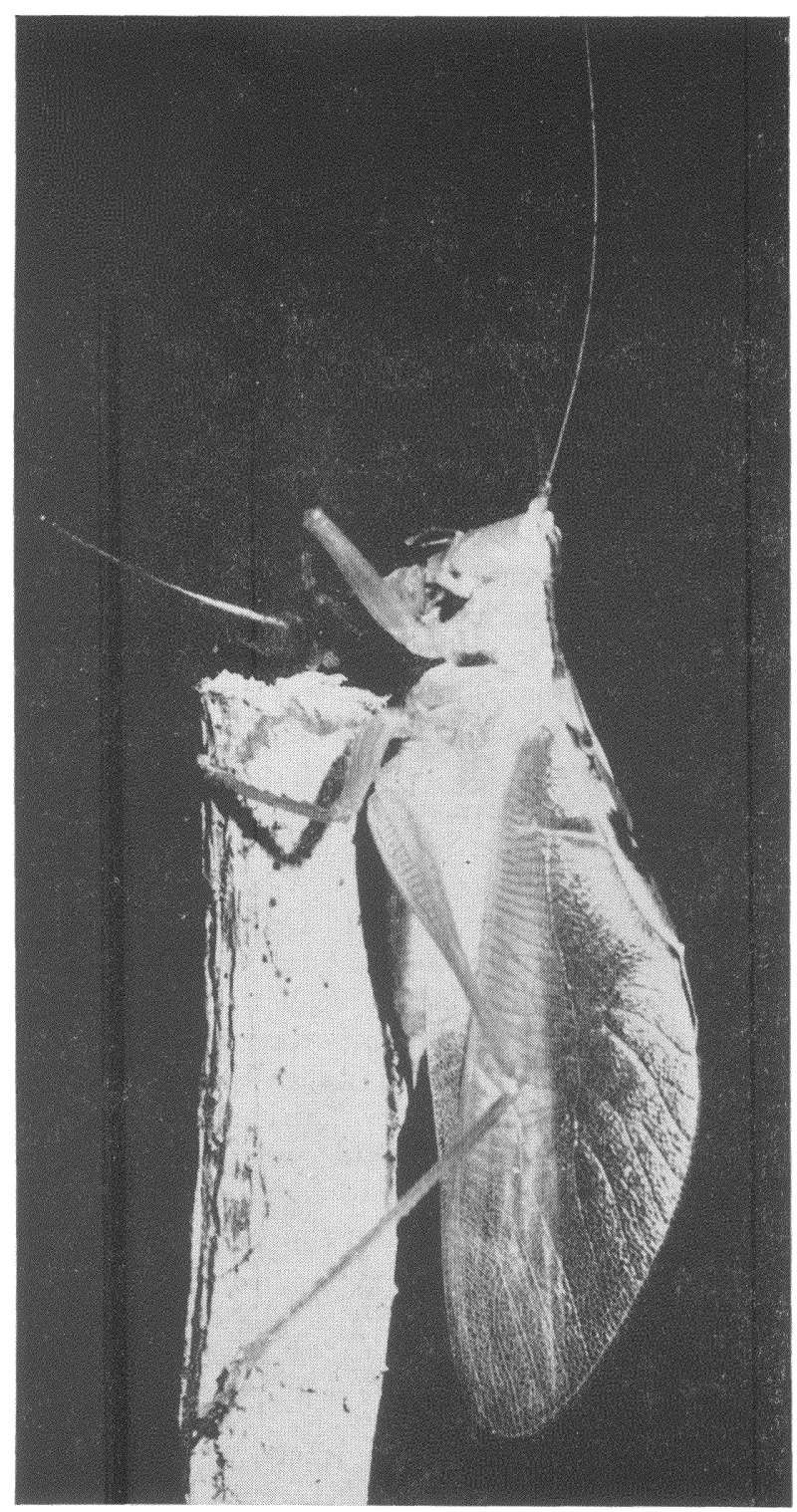

Figure 1. Male of Hexacentrus mundus feeding on small acridiid. Note that the prey is being held down by an anterior leg. Length ca. $60 \mathrm{~mm}$. 


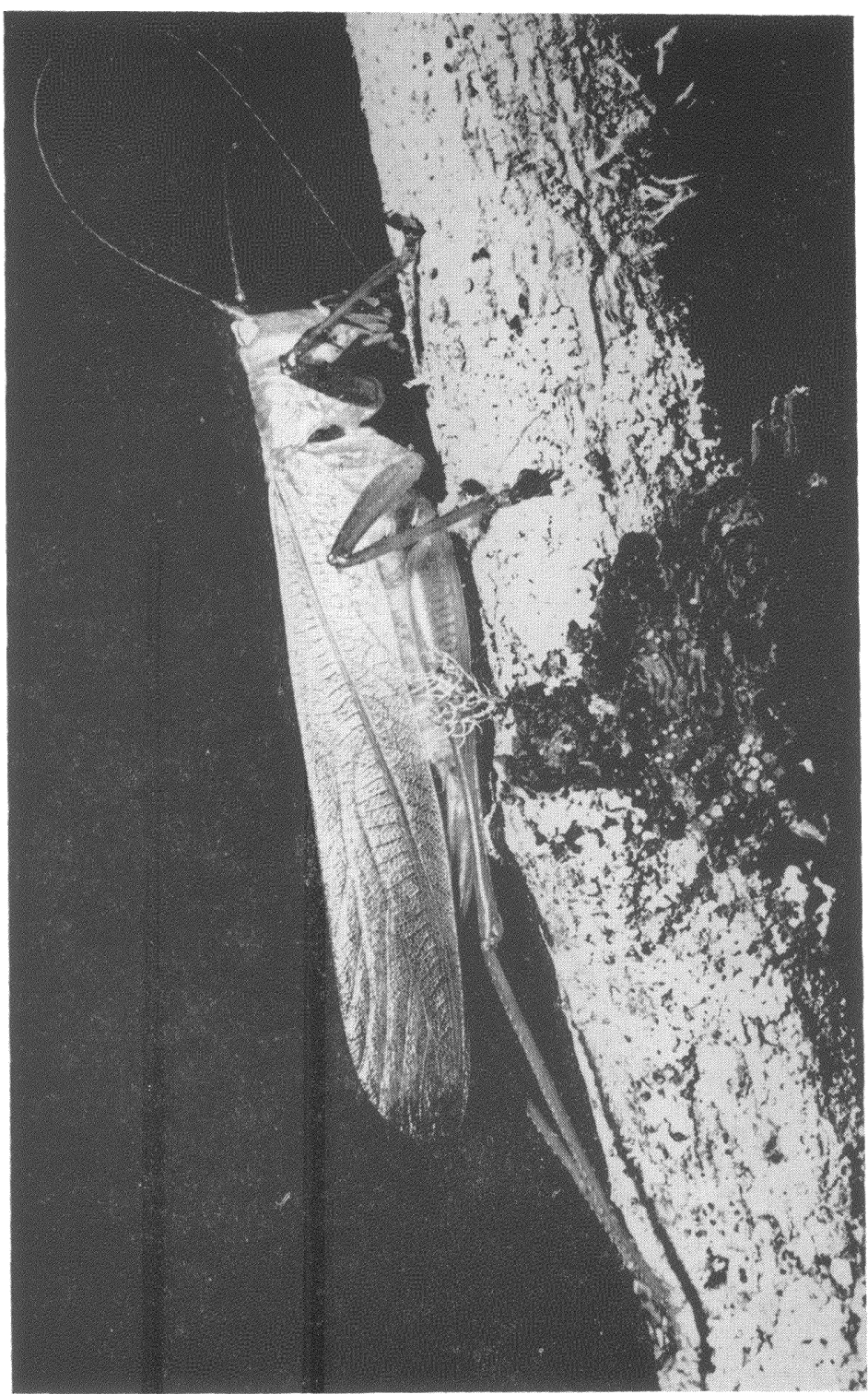


Figures $\mathrm{I}$ and 2 show the general appearance of male and female adults. The insect is grass green in color at all developmental stages and there is a quite distinct sexual dimorphism in the general shape of the resting adult. The dimorphism largely derives from a difference in the shape of the tegmina. Both sexes have large, widely spaced and projecting compound eyes, as have most predatory katydids. The tibiae of the anterior legs have rows of strongly developed spines with which the animal holds and restrains live prey (see Figure I). As far as we were able to determine the insect has no specialized cryptic or mimetic posture (unlike some of the other tettigoniids at Wau; see Robinson, 1973).

We originally considered the possibility that the species was predatory after an examination of its morphology. Later we found an adult male eating a large jumping spider that was obviously not carrion. This was the only instance we saw of predation in natural conditions (we never saw the species eating plant material at any stage). In captivity the insect caught and ate a variety of living insects and was particularly adept at catching calliphorid flies. These were caught if they settled close to the resting katydid; we did not see any stalking behavior. The katydid made a rapid forward lunge and then trapped the flies against the substrate beneath the spinous anterior tibiae. We saw nothing that was homologous to a mantid (or reduviid) strike, i.e., the anterior legs were not extended and then rapidly folded around the prey in a pincer grip. Figure I shows a male Hexacentrus feeding on an acridiid nymph which was caught after it had been left (by us) in a damaged condition in front of the katydid.

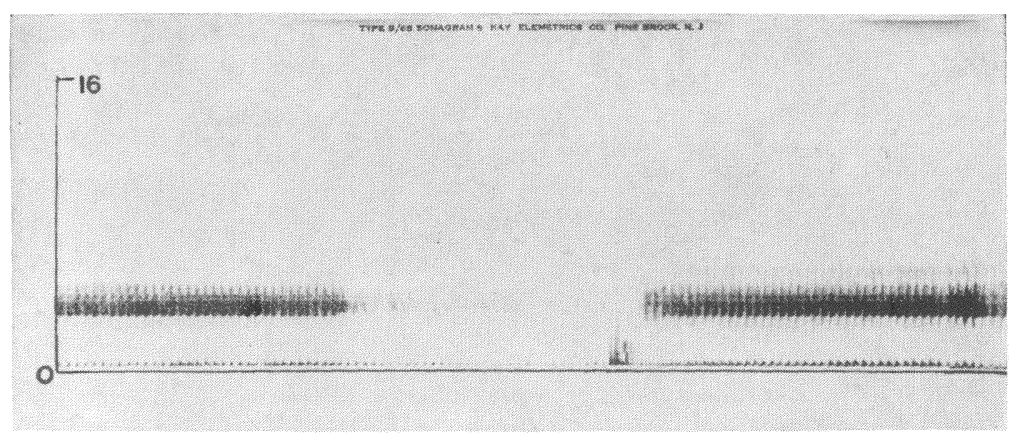

Figure 3. Sonagram of interrupted stridulation. Frequency range 0-16 $\mathrm{KHz}$. Time base 0.6 seconds. 
During the day the insect responded to the movements of flies by orienting towards them. The impression gained was that the animal was responding to visual stimuli. If feeding occurs principally at night (when stridulation occurs), visual prey detection seems less likely. We do not know that the animal is active only at night. In captivity it certainly feeds by day and in the wild it assumes positions, by day, on vegetation from which it could capture prey.

\section{The stridulation}

The males stridulate at night from the upper surface of leaves in secondary growth and in forest- and roadside-edge clearings. The stridulation is bisyllabic, "metallic," and repeated over lcng periods of time. Figure 3 shows sonagraphic representation of the sound. It is based on a recording made at $17 / 8$ inches per second on a Uher $3000 S$ tape recorder. Some harmonics are visible, but the frequency range of the principal stridulation is clearly visible in the sonagram.

Striduating males stand with their tegmina partly opened, i.e., the two tegmina are not touching along their posterior margins (which normally lie along the midline of the body when the insect is not in flight or singing).

The song of Hexacentrus mundus has all the characteristics of a calling song as defined and described by Dumortier. (1963).

\section{The census}

The census was carried out on one day per week between 2000 and 2100 hours, between $1.5-2$ hours after nightfall, irrespective of the weather conditions. Locations of the transects involved are shown diagramatically in Figure 4. They were always censused in the same order, I, II, and III. The technique was very simple. One of us simply walked along each transect to the end and back (transects I and III) or around twice (transect II), counting all the singing Hexacentrus that were audible on the two journeys. Individuals that were singing during both journeys were scored once only. From January to August (inclusive) the census was carried out by M.H.R.; T.P. carried out the remainder of the year's study.

The transects differed in vegetational structure Transect I was along an unpaved road flanked by uncut verges (I-I.5 meters wide) and bordering coffee plantations for most of its length (IOO meters). Transect II (ca. 200 meters) was around the outer perimeter of a garden which abutted coffee plantation around the entire length except for the short stretch of road shown in Figure 4. Transect III (I0O meters) was along a footpath connecting House 4 with the 
Table 1. Census results.

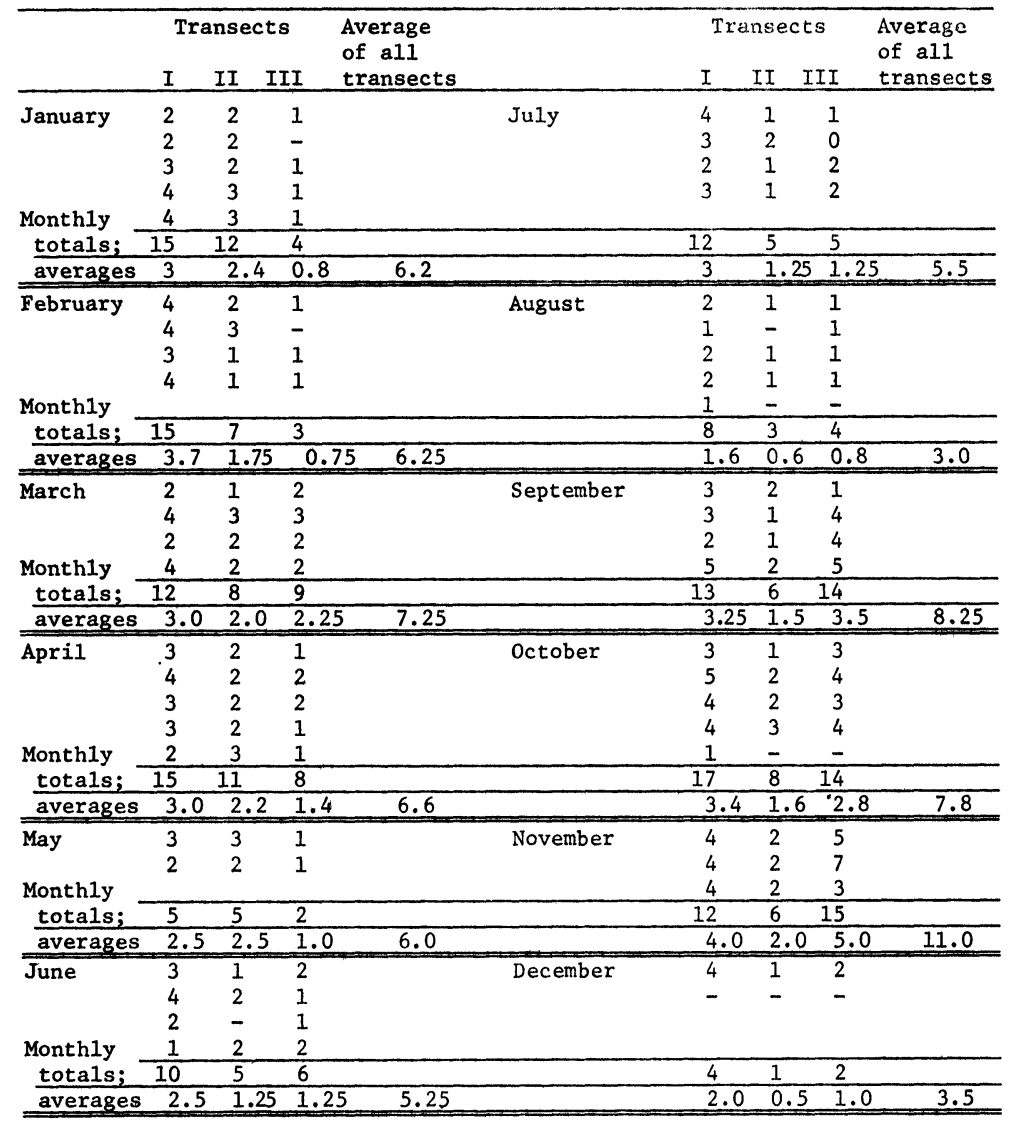

main building complex of Wau Ecology Institute. This footpath passed through coffee plantation edge for approximately one third of its length. The remainder of this transect ran through tall grass. All three transects were equally exposed; transects I and II were surrounded by trees and bushes.

\section{Results}

The weekly census totals and monthly averages are shown in Table I. Three month's censuses are incomplete. May is for only two weeks (MHR was absent from Wau), November is based on three weeks, and December is based on two weeks only (TP left 


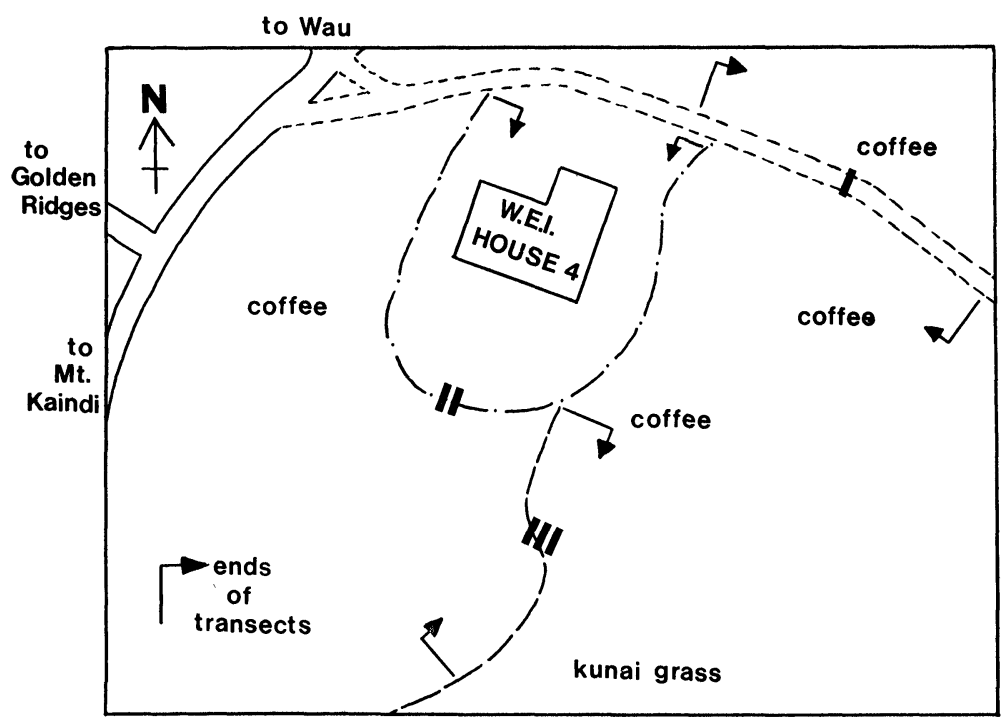

Figure 4. Sketch map of the location of the transects.

Wau; MHR left in September). We have graphed the monthly averages for each transect and the average for the combined monthly totals and these are shown in Figure 5.

\section{Discussion}

The sampling system that we used was not only simple but arbitrary. We did not attempt to determine whether the results were influenced by the weather conditions obtaining during the census period. We would guess that we were sampling a fairly high proportion of the males within earshot of the transects but that this proportion did not remain the same, necessarily, from census to census. We got the impression that fewer insects were singing on cold clear moonlit nights. Dumortier (1963; 638-9) lists a number of climatic variables that may affect insect song (either as exciters or inhibitors). For these reasons we would not place too much reliance on the magnitude of the variations in the census results. The direction of the variations may reflect some general trends, since the lowest counts occur towards the middle of the Southern Hemisphere winter when rainfall and temperatures at $W$ au are low (see Robinson, Lubin \& Robinson, I974: 132-3). 


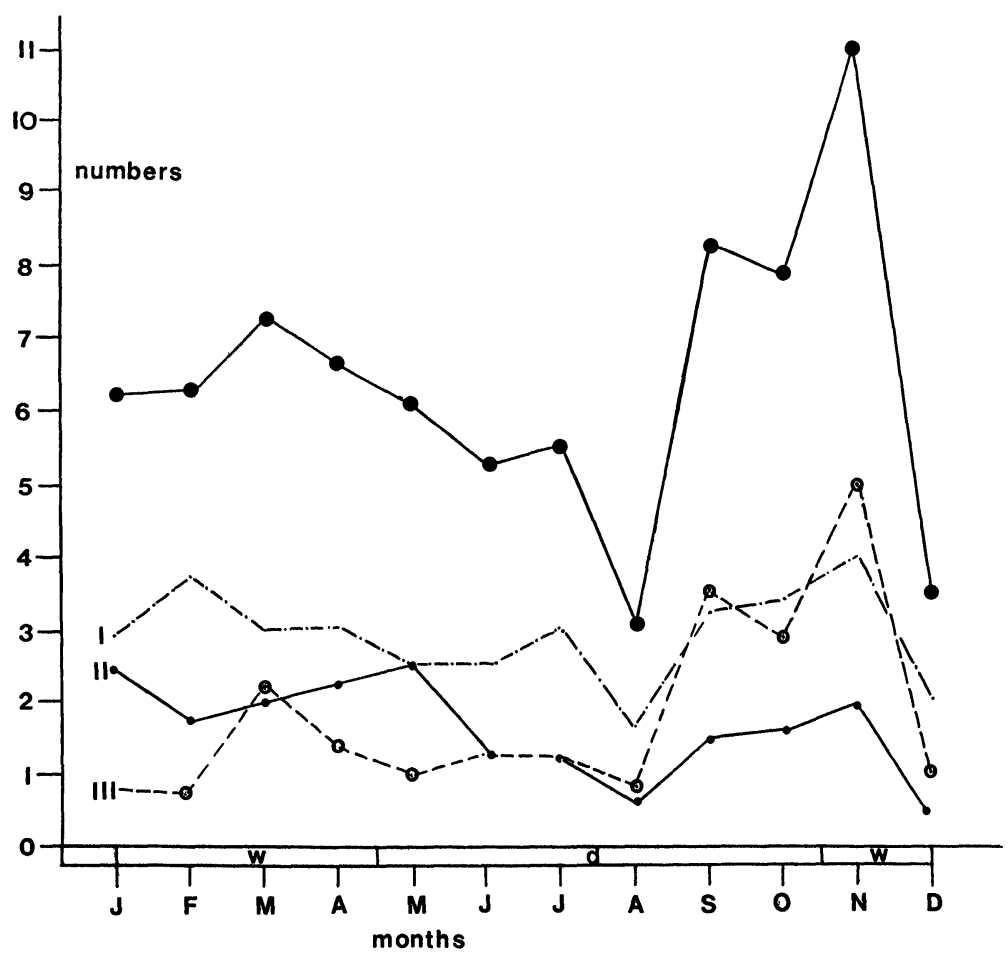

Figure 5. Graph of monthly average number of male Hexacentrus mundus stridulating on transects I, II, and III. Average for all transects marked A.

The most important conclusion that we draw from our data is that they are a reliable indication of year-round activity by a moderately large carnivorous insect. We strongly suspect that katydids in temperate regions will prove to be markedly seasonal in singing activity, reflecting the fact that adults are not present throughout the year. It would further seem probable that in temperate regions the larger the insect the shorter the portion of the year "occupied" by adults and we would expect that large katydids would be more seasonally restricted (as adults) than smaller species. (This should be generally true of temperate region arthropods that do not possess a pupal stage or cannot otherwise spread their development over more than one year, assuming it takes longer to reach a larger adult size, and that the overall period of each year available for active life is more or less equally restricted for all arthropods living under 
the same climatic regime.) Fulton's (195I) data for I9 species of North American orthopterans show that most of these sing at some stage during the period June to November.

If largish insects such as $H$. mundus exist on a year-round basis, as secondary consumers, it is possible that primary consumers may be similarly (relatively) aseasonal. Sustained coexistence (Robinson, Lubin \& Robinson, I974: I 58) of organisms over long periods of the year may be a situation with a high potential for generating species diversity. Thus, at the simplest level, it is possible to visualize the evolution of a predator specializing in large orthopterans only in a situation where, as at Wau, large orthopterans are present on a year-round basis.

\section{ACKNOWLEDGMents}

The work was carried out at Wau Ecology Institute, which supported T.P. in part. We are grateful to Dr. J. L Gressitt for use of the facilities at Wau. Donald Windsor prepared the sonagram.

\section{REFERENCES}

DUMORTIER, B.

1963. Ethological and physiological study of sound emissions in arthropods. In Busnel, R. G., ed., Acoustic Behaviour of Animals, Elsevier Publishing Co., Amsterdam, London, New York, pp. 583-584.

Fulton, B. B.

1951. The seasonal succession of orthopteran stridulation near Raleigh, North Carolina. J. Elisha Mitchell Sci. Soc. 67: 87-95.

Robinson, M. H.

1973. The evolution of cryptic postures in insects, with special reference to some New Guinea tettigoniids. Psyche 80: 159-165.

Robinson, M. H., Y. D. Lubin and B. Robinson.

1974. Phenology, natural history and species diversity of web-building spiders on three transects at Wau, New Guinea. Pacific Insects 20: $117-163$.

Robinson, M. H. AND B. Robinson.

1973. The ecology and behavior of the giant wood spider Nephila maculata (Fabricius) in New Guinea. Smithson. Contr. Zool. 149: 1-76. 

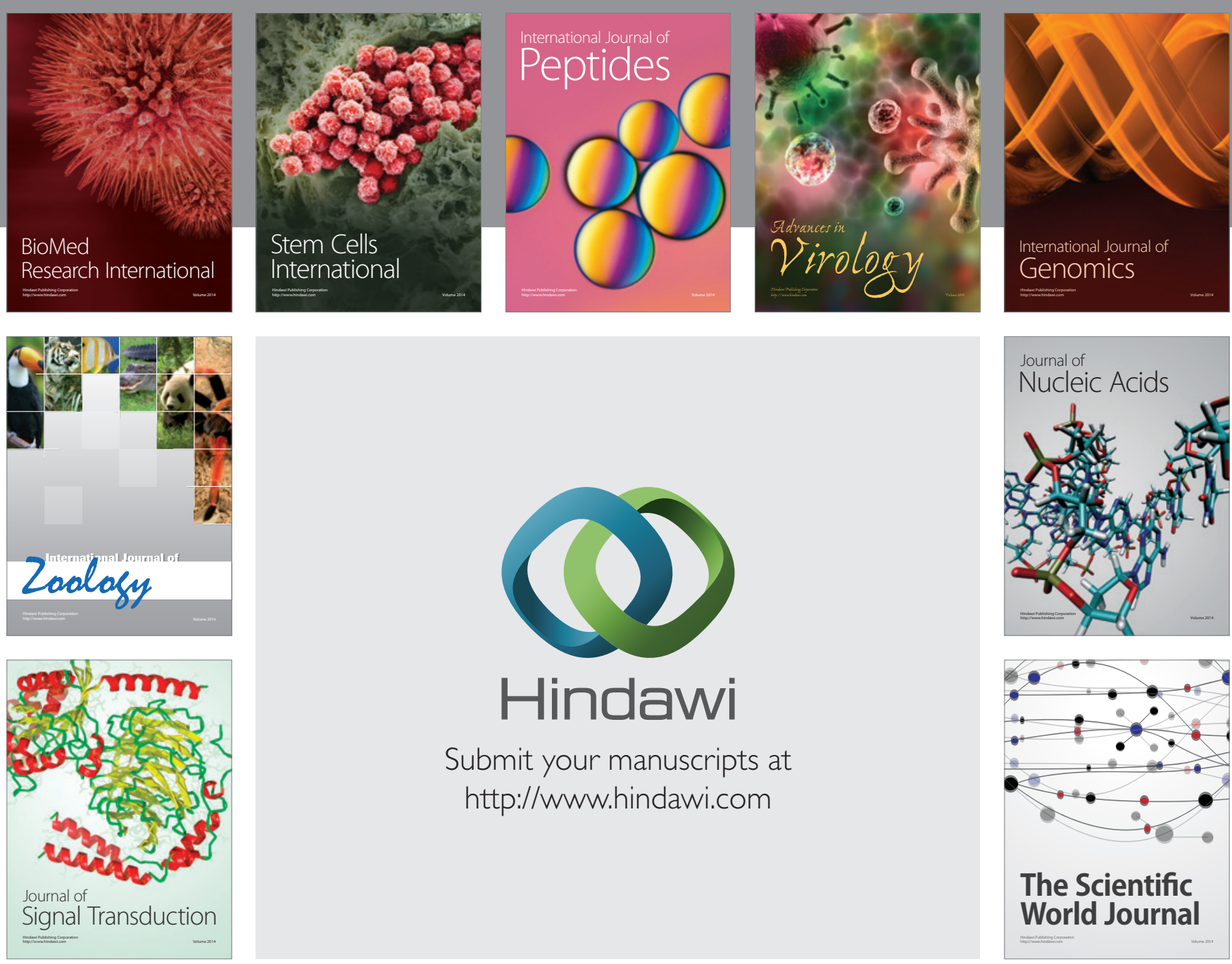

Submit your manuscripts at

http://www.hindawi.com
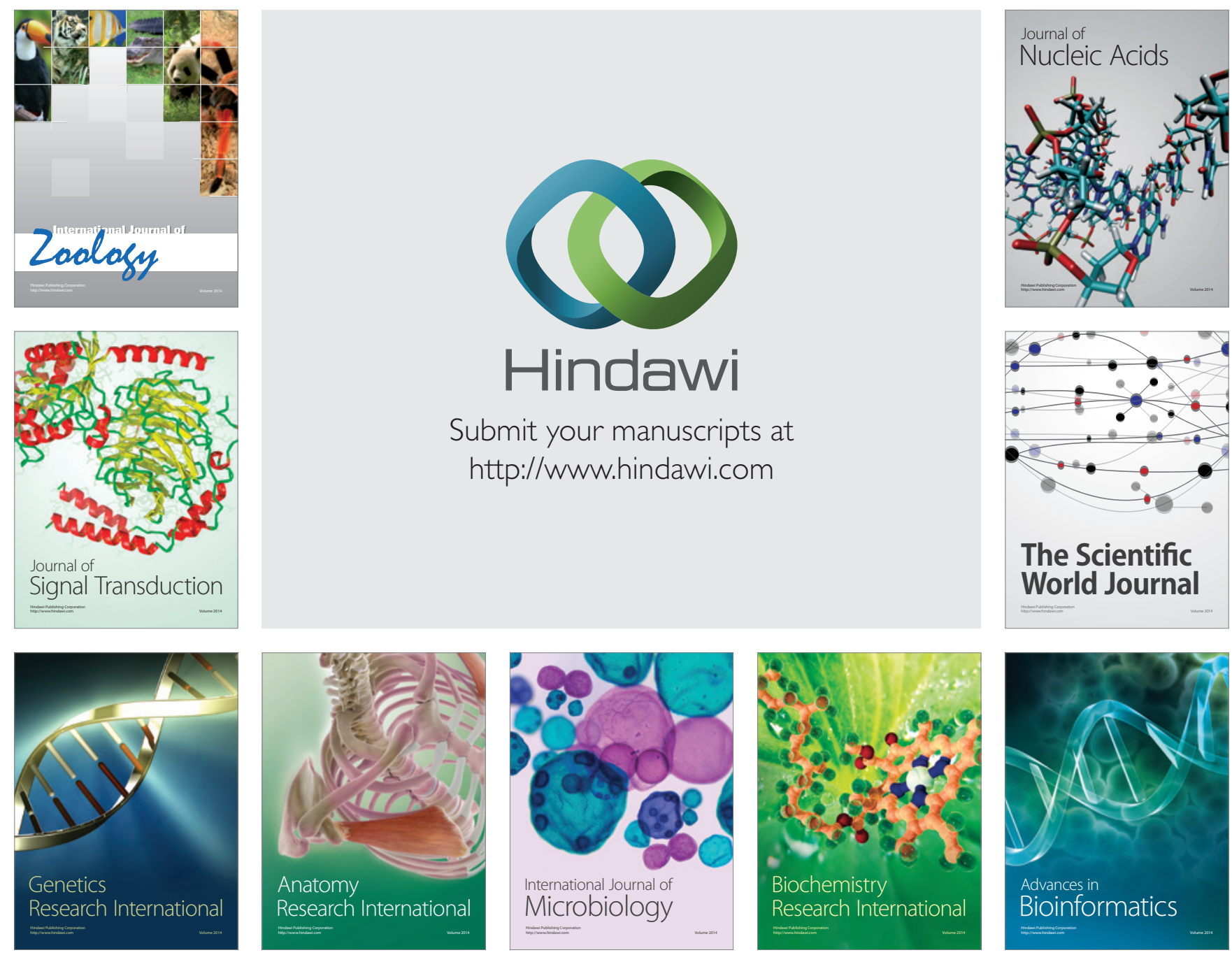

The Scientific World Journal
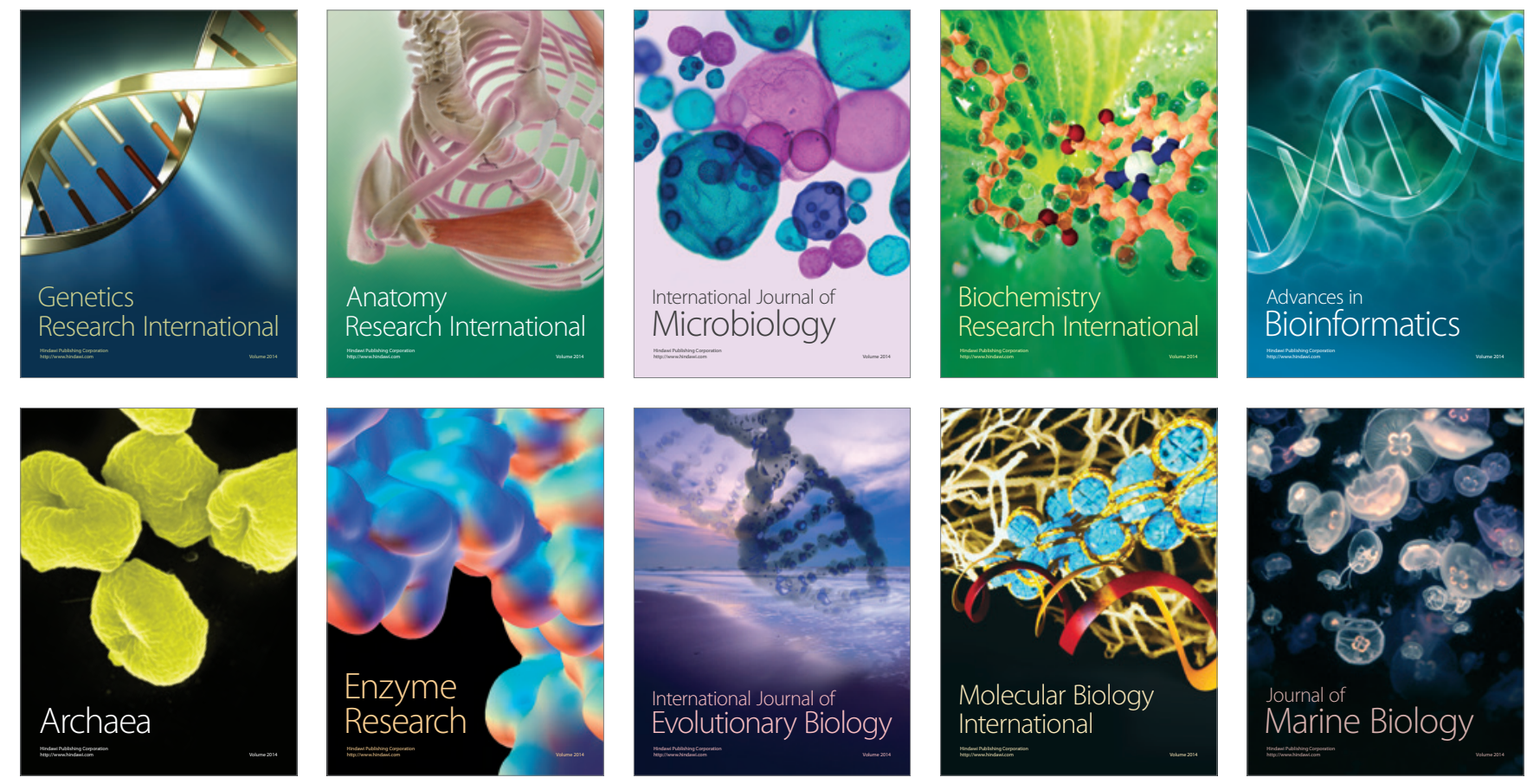